\title{
Estimates of maintenance requirement of growing lambs
}

\author{
BY D. J. THOMSON, J. S. FENLON AND S. B. CAM MELL \\ The Grassland Research Institute, Hurley, Maidenhead, Berkshire, SL6 ${ }_{5} L R$
}

(Received 9 March 1978 - Accepted I I September 1978)

\begin{abstract}
I. Total body energy retention (ER) and metabolizable energy intake (MEI) values from experiments with 23 I lambs (Suffolk o $\times$ (Border Leicester $\delta \times$ Cheviot $q$ ) $q$ ) housed indoors and given thirteen forage diets were used to estimate the metabolizable energy (ME) required for maintenance.

2. ER was measured using the comparative slaughter technique, and the lambs were fed at several planes of nutrition above maintenance between 2 and 5 months of age.

3. The daily ER and MEI results were scaled to live weight $\left(\mathrm{kg}^{0.75}\right)$ and linear regression lines fitted to the values for individual diets. Extrapolation of the fitted lines to zero ER gave estimates of maintenance requirement ranging from I $4 \mathrm{I}$ to $466 \mathrm{~kJ} \mathrm{ME} / \mathrm{kg}^{0.75}$ per $\mathrm{d}$ and values for the efficiency of utilization of $\mathrm{ME}$ for growth and fattening $\left(k_{f}\right)$ of $0.25-0.53$ (mean 0.39 ).

4. An alternative analysis constrained the estimated maintenance requirement to be the same for all diets. An iterative search procedure indicated minimal residual variation at $339 \mathrm{~kJ} / \mathrm{kg}^{0.75}$ per d. This common value of ME for maintenance gave $k_{f}$ values ranging from 0.30 to 0.54 (mean 0.39 ).

5. The implications of the technique were considered together with some discussion of the variability of the estimate. Allowing the minimum RSD to vary by $10 \%$ gave a maintenance requirement of between 231 and $408 \mathrm{~kJ} / \mathrm{kg}^{0.75}$ per d.
\end{abstract}

In the rationing of food, in the allocation of stock to a given area of land, as well as in the assessment of the nutritive value of a food fed at only one level of feeding, a knowledge of the maintenance requirement of the growing animal is required. Measurement of the utilization of the metabolizable energy (ME) of diets fed to growing and fattening ruminants has most frequently been made by calorimetry (Blaxter, I962). The same animal is fed at several different planes of nutrition above maintenance and sometimes at a maintenance level, and the slope of the linear regression line of energy retention (ER) on metabolizable energy intake (MEI) gives an estimate of the efficiency of utilization of metabolizable energy for growth and fattening $\left(k_{f}\right)$. An estimate of energy required for maintenance is obtained at zero ER.

The comparative slaughter technique (Thomson, I963; Garrett et al. 1964; Milford, 1965; Thomson, 1968) can be used to estimate ER, $k_{f}$ and also, by extrapolation, maintenance requirement. In this paper values for total body ER, obtained from comparative slaughter experiments, and MEI for growing lambs, between 2 and 5 months of age fed forage diets, were used to derive an estimate of energy requirement for maintenance. Some of the assumptions implicit in the regression model are discussed, and an approximate confidence bound is given to the estimate. The estimate is compared with those from other sources.

\section{MATERIALS AND METHODS}

\section{Animals and management}

Growing lambs (Suffolk $\hat{0} \times$ (Border Leicester $\delta \times$ Cheviot 9 ) ) ) were weaned at 5 weeks of age, and gradually established entirely on forage diets, before fasting ( $8 \mathrm{~h}$ ) and entry to an experiment at approximately 8-9 weeks of age. The lambs were housed indoors in metabolism cages and food was offered either once (09.30 hours) or twice daily (09.30 and 16.00 hours), in specified amounts adjusted weekly on the basis of live weight and the rate of gain of the individual lambs. The levels of feeding (two, three or four) ranged from 
Table I. The chopped $(C)$ and pelleted $(P)$ forage diets, levels of feeding, duration and the number of lambs used in experiments to determine energy retention and the efficiency of utilization of metabolizable energy for growth and fattening

\begin{tabular}{|c|c|c|c|c|c|}
\hline \multicolumn{2}{|r|}{ Diet } & \multirow{2}{*}{$\begin{array}{l}\text { Physical } \\
\text { form of } \\
\text { diet }\end{array}$} & \multirow{2}{*}{$\begin{array}{l}\text { No. of } \\
\text { levels of } \\
\text { feeding }\end{array}$} & \multirow{2}{*}{$\begin{array}{l}\text { Duration of } \\
\text { experiment } \\
\text { (d) }\end{array}$} & \multirow{2}{*}{$\begin{array}{l}\text { No. of } \\
\text { lambs }\end{array}$} \\
\hline No. & Forage & & & & \\
\hline I & Lucerne (Medicago sativa) & $\mathrm{C}$ & 3 & 100 & I5 \\
\hline 2 & Perennial ryegrass (Lolium perenne) & $\mathrm{C}$ & 2 & 70 & 16 \\
\hline 3 & Perennial ryegrass (L. perenne) & $\mathrm{C}$ & 2 & 70 & 16 \\
\hline 4 & Perennial ryegrass ( $L$. perenne) & C & 3 & 70 & 24 \\
\hline 5 & Italian ryegrass ( $L$. multiflorum) & $\mathrm{C}$ & 2 & 69 & 27 \\
\hline 6 & Perennial ryegrass (L. perenne) & $\mathrm{C}$ & $3^{*}$ & 67 & 12 \\
\hline 7 & Lucerne (M. sativa) & $\mathrm{p}$ & 3 & 100 & I5 \\
\hline 8 & Lucerne (M. sativa) & $\mathbf{p}$ & $4^{*}$ & 65 & 20 \\
\hline 9 & Lucerne ( $M$. sativa) & $\mathbf{P}$ & $4^{*}$ & 69 & 16 \\
\hline Io & Perennial ryegrass ( $L$. perenne) & $\mathbf{P}$ & $4^{*}$ & 69 & 20 \\
\hline II & Perennial ryegrass (L. perenne) & $\mathbf{P}$ & $4^{*}$ & 69 & 19 \\
\hline 12 & Red clover (Trifolium pratense) & $\mathrm{P}$ & $3^{*}$ & 71 & 15 \\
\hline 13 & Red clover ( $T$. pratense) & $\mathrm{P}$ & $4^{*}$ & 68 & 16 \\
\hline
\end{tabular}

* Includes ad lib. level of feeding.

ad lib. to allowances which permitted rates of live weight gain of not less than $80 \mathrm{~g} / \mathrm{d}$. With any one diet, the highest level of feeding, normally ad lib. or $90 \%$ of ad lib. intake dictated the allocation of food for other levels of feeding.

\section{Measurements}

All the lambs were housed indoors and the daily intake of food measured throughout the period of each experiment. The digestible and ME content of the forage diets was determined for each lamb at the level of feeding which appertained throughout the experimental feeding period. When urinary energy output had been measured, methane energy was calculated according to plane of nutrition and energy digestibility (Blaxter \& Clapperton, I965), and ME derived in the conventional manner as a percentage of the gross energy (GE) of the diet (Blaxter, 1962); alternatively it was estimated as 0.8I $\times$ digested energy (Agricultural Research Council, 1965). The ME values were then applied to the GE intake measurements for each individual lamb and MEI calculated as a mean daily value ( $\mathrm{MJ} / \mathrm{d})$ applicable over the period of experiment.

Total body ER (MJ/d) was measured as the difference between the final and initial total body energy content of each individual lamb. The total body energy content was obtained from the summation of the GE content of the carcass (plus head), internal organs and gut (empty), blood, wool and skin. The total body energy content of the lambs at the beginning of each experiment was estimated from linear regression equations relating total body energy content to fasted ( $18 \mathrm{~h}$ ) live weight derived from sample groups (between eighteen and twenty-three) of similar lambs. The technique has been described in detail for sheep (Thomson, 1963; Paladines et al. 1964; Milford, 1965; Thomson, 1968), and also for cattle (Garrett et al. 1964).

\section{Statistical analysis}

Both MEI and ER were scaled to metabolic live weight $\left(\mathrm{kg}^{0.75}\right)$, using the mean live weight of each animal, which was derived from the regression of live weight $v$. period of experiment. A series of regressions of ER $v$. MEI was determined for individual diets to estimate $k_{f}$ values (slope) and the MEI at zero ER (maintenance requirement for ME). An alternative regression 
Table 2. Estimates of the daily requirement of metabolizable energy (ME) for maintenance of lambs, and the determined efficiency of utilization of $\mathrm{ME}$ for growth and fattening $\left(k_{f_{1}}\right)$ and the efficiency $\left(k_{f_{2}}\right)$ derived using a common maintenance value of $339 \mathrm{~kJ} \mathrm{ME} / \mathrm{kg}^{0.75}$ per $d$

(Figures in parentheses are the $90 \%$ tolerance limits for the estimated maintenance value)

\begin{tabular}{|c|c|c|c|c|c|}
\hline Diet no.* & $\begin{array}{l}\text { Estimate of ME for } \\
\text { maintenance }\left(\mathrm{kJ} / \mathrm{kg}^{0.75} \text { per } \mathrm{d}\right)\end{array}$ & $r$ & RSD & $k_{f_{1}}$ & $k_{f_{2}}$ \\
\hline I & $(48,423)$ & 0.75 & 23.0 & 0.28 & 0.30 \\
\hline 2 & $376 \quad(224,468)$ & 0.88 & 20.0 & 0.36 & 0.33 \\
\hline 3 & $229(-81,382)$ & $0.8 \mathrm{I}$ & $20 \cdot 7$ & 0.28 & 0.34 \\
\hline 4 & $396 \quad(284,465)$ & 0.84 & 24.9 & 0.38 & 0.33 \\
\hline 5 & I4I $(-293,334)$ & 0.68 & $28 \cdot 8$ & 0.25 & 0.35 \\
\hline 6 & $225(-60,364)$ & 0.86 & $22 \cdot 7$ & 0.43 & 0.54 \\
\hline 7 & $(280,415)$ & 0.90 & $2 I \cdot 4$ & 0.53 & 0.49 \\
\hline 8 & $353 \quad(294,396)$ & 0.93 & I $8 \cdot 9$ & 0.43 & 0.42 \\
\hline 9 & $(314,514)$ & 0.89 & $22 \cdot I$ & 0.38 & 0.30 \\
\hline IO & $(175,469)$ & 0.83 & $24 \cdot I$ & 0.37 & 0.36 \\
\hline II & $(296,556)$ & 0.80 & $28 \cdot I$ & 0.48 & 0.36 \\
\hline 12 & $310 \quad(110,421)$ & 0.86 & $27 \cdot 1$ & 0.46 & 0.49 \\
\hline 13 & $340 \quad(208,416)$ & 0.87 & $2 I \cdot 6$ & 0.46 & 0.46 \\
\hline
\end{tabular}

model was assumed, in which the estimate of maintenance MEI was deemed to be the same for all diets.

This results in a series of lines of different slope emanating from a single point $\left(X_{0}, 0\right)$ on the $x$-axis. This type of model has been discussed extensively by Williams (1959) and in the instance of unknown $X_{0}$ does not provide an analytical solution except where the values have a particular structure; where $X_{0}$ is known the other criteria in the model can be determined by simple least squares. The value of $X_{0}$ which minimized the residual sum of squares for the model was determined by a simple search along the $x$-axis, and the remaining criteria were taken as corresponding to the simple least squares solution at that point.

\section{RESULTS}

The results of the individual regressions for each diet are shown in Table 2. The thirteen diets gave estimated ME intakes at zero energy retention between I 4 I and $466 \mathrm{~kJ} / \mathrm{kg}^{0.75}$ per d, with efficiencies $\left(k_{f_{1}}\right)$ of 0.25 to 0.53 . Under the alternative hypothesis of a common maintenance intake for all diets minimal residual variation was exhibited at $339 \mathrm{~kJ} \mathrm{ME} / \mathrm{kg}^{\mathbf{0 . 7 5}}$ per d (Fig. I) with $k_{f_{2}}$ values between 0.30 and 0.54 , as shown in Table 2. From a statistical point of view the additional variance accounted for by fitting separate regressions to each diet compared with the variance accounted for by regressions constrained to a common intercept for all diets was not significant, so that the latter model is preferred.

The provision of tolerance limits for the estimate of MEI at zero ER is not straightforward (Williams, 1959), and they have not been determined in this analysis. Fig. I demonstrates the effect on the residual mean square of changing the estimate of MEI at zero ER. It can be seen that the shape of the curve is markedly non-symmetric about the minimum value, and although the response is fairly insensitive for values of $\mathrm{MEI}$ below $339 \mathrm{~kJ} / \mathrm{kg}^{0.75}$ per d, it increases rapidly for values above 339 : if the residual mean square is permitted to vary by up to $10 \%$ of its minimum value then the estimate of maintenance could lie between $23 \mathrm{I}$ and $408 \mathrm{~kJ} / \mathrm{kg}^{0.75}$ per $\mathrm{d}$.

The third and fourth columns of Table 2 give the approximate $90 \%$ tolerance limits for 


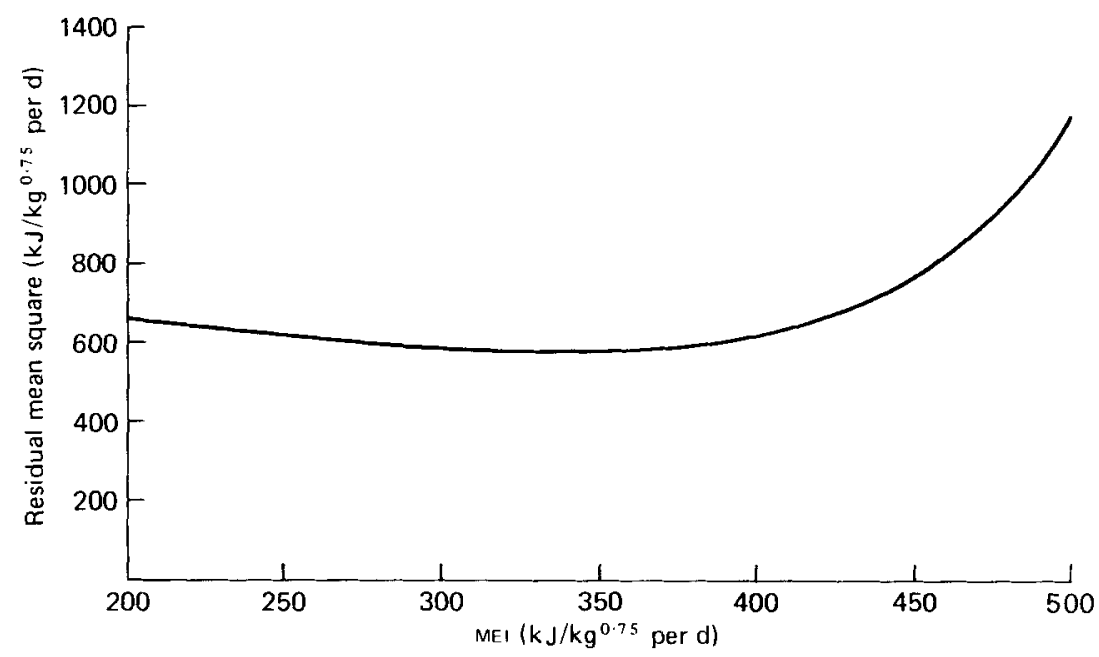

Fig. 1. The pooled residual mean square $\left(\mathrm{kJ} / \mathrm{kg}^{0.75}\right.$ per $\left.\mathrm{d}\right)$ in relation to metabolizable energy intake (MEI $; \mathrm{kJ} / \mathrm{kg}^{\mathbf{0 . 7 5}}$ per d) (the minimum of the curve represents the least-squares estimate of maintenance requirement of $\mathrm{ME}$ ) for $23 \mathrm{I}$ lambs housed indoors and given thirteen forage diets.

the estimates of MEl at maintenance for each diet (Williams, 1959). In general these are quite wide since in all cases an extrapolation is required from the data values to the MEI axis. Intuitively the common intercept would have a more compact tolerance interval since all the data sets reinforce each other. Fig. 2 demonstrates the widening of the confidence intervals as the fitted unconstrained line is extrapolated for three separate diets; the constrained line is also shown. Two of the diets represent the extremes of estimated maintenance requirement while the third has the same parameters for both the unconstrained and the constrained models.

\section{DISCUSSION}

Use of results from this type of study necessitates extrapolation from a cluster of points to the horizontal axis for an estimate of MEI at maintenance. Inevitably this creates large errors and wide tolerance limits for the estimated intercept. This is amply demonstrated in Table 2. There are two further problems: what exponent of body-weight should be used to scale the measured data, and should the relationship be curvilinear?

It has been conventional to scale according to metabolic live weight, using an exponent of 0.75 (Kleiber, 1963), and that convention has been followed here. The actual exponent of body-weight used has little influence on the general conclusion of this study, since mean live weights of the lambs used in all the experiments were within a narrow range, consequently the scaling would only slightly perturb the basic relationship. However, a nonlinear regression model was used to determine the optimum exponent of body-weight in the range $0.5^{-1} \cdot 0$ for each diet. The result was inconclusive (only five diets chose intermediate values with one on the upper boundary and seven on the lower) and it was decided to retain the exponent $0 \cdot 75$.

The relationship between ER and MEI is generally held to be curvilinear over a wide range (Blaxter \& Boyne, 1970) though it is frequently approximated by two straight lines (Webster, 1978). The results illustrated in Fig. 2 are typical of those for other experiments in which ER is measured with growing animals by the comparative slaughter technique, and though the values for an individual diet are clustered there is nothing to suggest a curvilinear response. If the true relationship between ER and MEI is curvilinear, then the implication is 

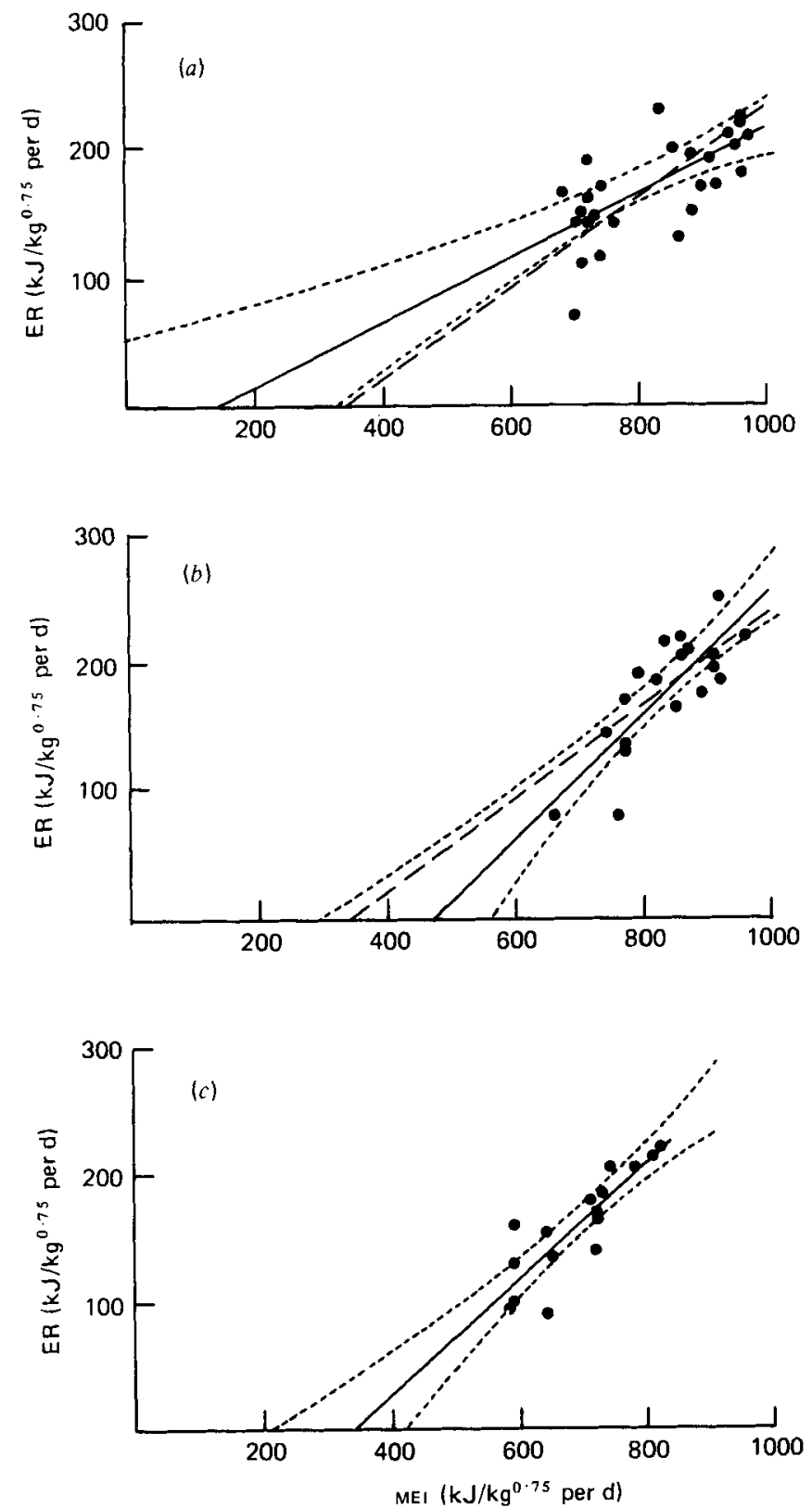

Fig. 2. Energy retention (ER; $\mathrm{kJ} / \mathrm{kg}^{0.75}$ per d) $v$. metabolizable energy intake (MEI; $\mathrm{kJ} / \mathrm{kg}^{0.75} \mathrm{per}^{\mathrm{d}}$ ) for sheep housed indoors and given diet nos. 5(a), I I (b) and I3 (c) (for details, see Table I), indicating the difference between the unconstrained least-squares fit $(-\longrightarrow)$ and that forced through the point $\left(339^{\circ}\right)(--)$. For diet no. 13 the lines are coincident. The $90 \%$ confidence limits for the fitted line are shown (----) for each diet. 
Table 3. Estimates of the maintenance requirement $(M J / d)$ of growing lambs

\begin{tabular}{|c|c|c|c|c|c|c|}
\hline \multirow[b]{2}{*}{ Source } & \multicolumn{6}{|c|}{ Live wt (kg) } \\
\hline & 20 & 25 & 30 & 35 & 40 & 45 \\
\hline Agricultural Research Council (1965) & $3 \cdot 87$ & $4 \cdot 49$ & $5 \cdot 09$ & $5 \cdot 64$ & $6 \cdot 18$ & $6 \cdot 72$ \\
\hline Forbes \& Robinson (1969) & - & $3 \cdot 76$ & $4 \cdot 4 \mathrm{I}$ & 4.99 & $5 \cdot 63$ & $6 \cdot 27$ \\
\hline Graham \& Searle (1972) & $3 \cdot 4 I$ & 4.02 & $4 \cdot 62$ & $5 \cdot 18$ & $5 \cdot 73$ & $6 \cdot 25$ \\
\hline MAFF (1975) & $3 \cdot 80$ & $4 \cdot 45$ & $5 \cdot 10$ & $5 \cdot 75$ & $6 \cdot 40$ & $7 \cdot 05$ \\
\hline Ørskov \& McDonald (1970) & $\rightarrow$ & $4 \cdot 68$ & $5 \cdot 36$ & $6 \cdot 02$ & $6 \cdot 66$ & $7 \cdot 27$ \\
\hline Simpson (I976) & $3 \cdot 22$ & $3 \cdot 80$ & $4 \cdot 36$ & $4 \cdot 89$ & $5 \cdot 41$ & 5.91 \\
\hline Present study & $3 \cdot 22$ & 3.80 & $4 \cdot 36$ & $4 \cdot 89$ & $5 \cdot 41$ & 5.91 \\
\hline
\end{tabular}

that estimates of maintenance energy requirement determined by linear extrapolation are too low.

The value for maintenance requirement obtained in this study is virtually identical to that of $340 \mathrm{~kJ} / \mathrm{kg}^{0.75}$ per $\mathrm{d}$ obtained by Simpson (1976) for lambs who measured energy retention in respiration chambers. Additionally, the values obtained by Forbes and Robinson (1969) in growth experiments conducted at two planes of nutrition are very similar to the estimate obtained in the present work.

In Table 3 the values for the ME requirement for maintenance proposed by the Agricultural Research Council (1965) and adopted by the Ministry of Agriculture, Fisheries and Food (1975), are compared with other published values for growing lambs in the postweaning phase of growth. The calorimetric estimates of Graham \& Searle (1972) were obtained by interpolation from the values they obtained at 3 and 6 months of age and are $5 \%$ higher than the estimate from the present work. Ørskov \& McDonald (1970) obtained their estimates of maintenance as the constant term from a multiple regression analysis partitioning the energy cost of fat and protein deposition in lambs which were sustaining high rates of gain. Their estimates are high relative to other published values and also when compared with the Agricultural Research Council (1965) and the Ministry of Agriculture, Fisheries and Food (1975) values given in Table 3.

Approximate limits for the estimated maintenance value were presented earlier and these can be seen to correspond fairly well with the $90 \%$ tolerance limits presented in Table 2 for each individual diet. The upper limit of $408 \mathrm{~kJ} / \mathrm{kg}^{0.75}$ per $\mathrm{d}$ gives maintenance requirements corresponding almost exactly with the recommendations of the Ministry of Agriculture, Fisheries and Food (1975).

The authors would like to thank Mr M. C. Spooner, Mr G. Kiernan and Mrs A. Jones for technical help, Mr R. A. Barnes for chemical analyses, and a referee for some helpful suggestions.

\section{REFERENCES}

Agricultural Research Council (1965). The Nutrient Requirements of Farm Livestock. No. 2. Ruminants. London: H.M. Stationery Office.

Blaxter, K. L. (1962). The Energy Metabolism of Ruminants. London: Hutchinson.

Blaxter, K. L. \& Boyne, A. W. (1970). Publs. Eur. Ass. Anim. Prod. 13, 9.

Blaxter, K. L. \& Clapperton, J. L. (I965). Br. J. Nutr. I9, 5 I I.

Forbes, T. J. \& Robinson, J. J. (I969). Anim. Prod. Ir, 389.

Garrett, W. N., Lofgreen, G. P. \& Meyer, J. H. (1964). J. Anim. Sci, 23, 470.

Graham, N. Mc. \& Searle, T. W. (I972). J. Agric. Sci., Camb. 79, 383.

Kleiber, M. (1963). Publs. Eur. Ass. Anim. Prod. 11, 427.

Milford, R. (1965). Herbage digestibility and animal production. PhD Thesis, University of Reading.

Ministry of Agriculture, Fisheries and Food (1975). Tech. Bull. no. 33.

Ørskov, E. R. \& McDonald, I. (1970). Publs Eur. Ass. Anim. Prod. 13, 12 I. 
Paladines, O. L., Reid, J. T., van Niekerk, B. D. H. \& Bensadoun, A. (1964). J. Nutr. 83, 49.

Simpson, A. M. (1976). A study of the energy metabolism and seasonal cycles of captive red deer. PhD

Thesis, University of Aberdeen.

Thomson, D. J. (1963). Publs. Eur. Ass. Anim. Prod. 11, 319.

Thomson, D. J. (1968). The utilization of herbage diets by growing sheep. PhD Thesis, University of Reading.

Webster, A. J. F. (1978). Wld Rev. Nutr. Diet. 3o, 189.

Williams, E. J. (1959). Regression Analysis. New York: Wiley. 